\title{
Isolation of Embryonic Chick Motoneurons and Their Survival in vitro
}

\author{
Richard J. O'Brien' ${ }^{1}$ and Gerald D. Fischbach \\ Department of Anatomy and Neurobiology, Washington University School of Medicine, St. Louis, Missouri 63110
}

This is the first of a series of 4 papers in which we describe the regulation of excitatory amino acid receptors on embryonic chick motoneurons dissociated from the lateral motor column and maintained in cell culture. Techniques are described for labeling embryonic chick motoneurons in vivo with Lucifer Yellow or fluorescein isothiocyanate conjugates of wheat germ agglutinin (Fl-WGA). We estimate that 65-95\% of the motoneurons in the lateral motor column survive tissue dissociation and settle on an appropriate culture surface. The number of fluorescent motoneurons observed in heterogeneous spinal cord cell cultures decreases with a half-life of $\mathbf{2} \mathrm{d}$. The decline is due to fading of the fluorescent tracer rather than to loss of cells. Techniques are also described for separating motoneurons from other spinal cord cells with a fluorescence-activated cell sorter. Approximately $24 \%$ of the motoneurons in the lateral motor column can be isolated, and motoneurons comprise more than $90 \%$ of the population in cultures seeded with sorted cells.

The survival of sorted and unsorted motoneurons in vitro is enhanced in the presence of skeletal myotubes or muscle conditioned medium, but the survival of non-motoneurons is not influenced by muscle.

Electrophysiologic properties of sorted and unsorted motoneurons determined with patch-clamp techniques are similar. Both differ from mature motoneurons in their lower resting membrane potential $(-50 \mathrm{mV})$, larger input resistance $(450 \mathrm{M} \Omega)$, and longer time constant $(39 \mathrm{msec})$. Also they do not exhibit anomalous rectification or a calcium-activated potassium after hyperpolarization.

Motoneurons grown in the absence of interneurons differ from motoneurons in heterogeneous spinal cord cell cultures in that their neurites (dendrites) are shorter and they branch less often.

Motoneurons in the anterior horn of the spinal cord are among the best-studied neurons in the adult CNS. They are large and easy to penetrate with microelectrodes, they can be identified unambiguously following stimulation of ventral roots and peripheral nerves, and their synaptic inputs have been characterized in considerable detail (see reviews by Burke and Rudomin, 1977; Redman, 1979; Schwindt and Crill, 1984). We are interested in the regulation of chemoreceptors on embryonic motoneurons during the process of synapse formation. However, it has been difficult to perform precise pharmacological analyses

\footnotetext{
Received Jan. 14, 1986; revised Apr. 25, 1986; accepted May 5, 1986.

We are grateful to Drs. Richard Hume, Lorna Role, Ted Usdin, and David Gottlieb for helpful discussions, to Drs. Charles Zorumski and Jay Yang for comments on the manuscript, to Mr. Robert Weber for his careful maintenance of the FACS IV, and to Dr. Walter Stewart for his gift of Lucifer Yellow-VS. This work was supported by USPHS Grant NS 18458 (G.D.F.) and by Harvard Medical School Medical Scientist Training Program T32 GM07753 (R.O.).

Correspondence should be addressed to Gerald D. Fischbach, Department of Anatomy and Neurobiology, Washington University School of Medicine, 660 South Euclid Ave., St. Louis, MO 63110.

' Present address: Department of Medicine, Massachusetts General Hospital, Fruit Street, Boston, MA 02114.

Copyright (C) 1986 Society for Neuroscience $0270-6474 / 86 / 113265-10 \$ 02.00 / 0$
}

in the intact cord that might aid in the unambiguous identification of particular neurotransmitters and characterization of postsynaptic receptors. The small size of motoneurons in young embryos during the time of synapse formation presents an additional problem.

Dissociated spinal cord cell cultures offer definite advantages for studies of synapse formation (Fischbach and Nelson, 1977). They are simplified in that the neurons are not encased in glia and, hence, are directly accessible to microelectrodes and applied drugs. However, such cell cultures remain complex in that they contain many different types of neurons and non-neuronal cells. Attempts have been made to purify motoneurons based on their size or density (Berg and Fischbach, 1978; Schnaar and Schaffner, 1981) or by dissociating cells from young embryos before many of the interneurons have been born (Berg and Fischbach, 1978; Masuko et al., 1974). These approaches have met with some success based on the measured increase in specific activity of choline acetyltransferase; however, they do not allow one to identify a particular cell as a motoneuron. Recently, this problem was solved by labeling embryonic motoneurons via retrograde transport of Lucifer Yellow (LY) and fluorescein conjugates of wheat germ agglutinin (Fl-WGA) (McPhecters and Okun, 1980; Okun, 1981). The tracer is retained in motoneuron cell bodies when their dendrites and axons are stripped away during the process of dissociation, and the motoneurons can be identified in vitro by fluorescence microscopy. Others have used the same or different fluorochromes to label a variety of neurons in situ prior to dissociation (Armson and Bennett, 1983; Calof and Reichardt, 1984; Eagleson and Bennett, 1983; Huettner and Baughman, 1984; Leifer et al., 1984; Sarthy et al., 1983; Schaffner et al., 1983). Once dissociated, the labeled cells can be separated from other spinal cord cells with a fluorescence-activated cell sorter. This ability to grow motoneurons in the presence and absence of other spinal cord cells allows one to ask how interneurons affect the distribution of motoneuron chemoreceptors.

In the following 3 papers we characterize the types of excitatory amino acid receptors on embryonic chick motoneurons (O'Brien and Fischbach, 1986a), identify the role of each in synaptic transmission (O'Brien and Fischbach, 1986b), and finally demonstrate their regulation by interneurons and by amino acid receptor agonists (O'Brien and Fischbach, 1986c). Here, we describe our methods for labeling and sorting embryonic chick motoneurons and our attempts to define conditions for promoting their survival and growth in vitro.

The study of motoneuron survival in culture is important for 2 reasons. First, it is necessary to define optimal culture conditions in order to maximize the likelihood that differences observed between motoneurons grown alone and motoneurons grown together with other spinal cord cells result from specific inductive interactions rather than from a more general effect on the health of the cells. Second, study of cell survival in vitro may shed light on the maturation and survival of motoneurons in vivo. As is true of large "output" neurons throughout the neural tube, motoneurons are among the first born in the spinal 
cord. In the chick, most cells destined for the lateral motor column have withdrawn from the mitotic cycle and have migrated away from the germinal epithelium by the 4 th or 5 th day of embryonic life (Hamburger, 1948; Hollyday and Hamburger, 1977). The first axons emerge from the neural tube during the 2nd day after fertilization, and by the 5th day nearly all of the motoneurons have extended processes to the periphery (ChuWang and Oppenheim, 1978; Hamburger, 1975; Landmesser, 1978; Ramón y Cajal, 1929). Between embryonic days 6 and 9, approximately $40 \%$ of the motoneurons in the lateral motor column of lumbar segments degenerate (Hamburger, 1975). Transplantation of a supernumerary limb prevents most of this naturally occuring cell death (Hollyday and Hamburger, 1976), whereas amputation of the limb leads to a loss of all motoneurons (Hamburger, 1958; Oppenheim et al., 1978), so it is generally assumed that a target-derived factor is necessary for the survival of embryonic motoneurons (see reviews by Cunningham, 1982; Oppenheim, 1981).

We have therefore focused on the effect of embryonic myotubes, myotube-conditioned medium, and an extract prepared from whole chick embryos on the survival of motoneurons in culture. In most previous work, the survival of spinal cord neurons and the initial outgrowth of neurites have been followed for only 1 or $2 \mathrm{~d}$ in culture. Because we are interested in events associated with synapse formation that might not occur during this short interval, we monitored the number of cells and their dendritic arbors over a longer period of time. A preliminary account of some of these experiments has been published $\left(\mathrm{O}^{\prime}\right.$ Brien and Fischbach, 1983; O'Brien ct al., 1982).

\section{Materials and Methods}

\section{Preparation of fluorescent tracers}

Fluorescein and LY conjugates of wheat germ agglutinin (WGA) were prepared by a modification of the procedure described by Okun (1981). Fluorescein isothiocyanate, $1.2 \mathrm{mg}$ (Sigma) or $1.0 \mathrm{mg}$ of the vinyl sulfone form of LY (LY-VS; generously supplied by Dr. W. Stewart) were dissolved in $75 \mu \mathrm{l}$ of $0.15 \mathrm{M}$ borate buffer, $\mathrm{pH} 9.0$, along with $0.65 \mathrm{mg}$ of WGA (E.Y. Labs) and incubated for $3 \mathrm{hr}$ at $37^{\circ} \mathrm{C}$. Uncoupled fluorochromes were separated from the WGA conjugates by centrifugation through a Sephadex G-25 minicolumn preequilibrated with $0.1 \mathrm{~mm}$ phosphate buffer, $\mathrm{pH}$ 7.0. Conjugates were freshly prepared on the day of use.

\section{Labeling of motoneurons}

Hindlimbs of 5-d-old chick embryos were injected as follows. The shell above the air sac was chipped away with blunt forceps. The thick outer membrane was peeled back, and an incision made in the chorioallantoic membrane with iridectomy scissors, taking care to avoid blood vessels and the yolk sac. One leg was drawn through the incision with fine forceps, and a total of $2 \mu \mathrm{l}$ of fluorescent tracer was injected into 10-15 sites in the thigh and shank. A micropipette, pulled on a conventional electrode puller and broken to a tip diameter of $5 \mu \mathrm{m}$, was used to inject the compound at a pressure of $10 \mathrm{psi}$. The shell was closed with parafilm and sealed with vacuum grease, and the egg was returned to the incubator for $16 \mathrm{hr}$. We routinely injected 10-20 embryos at a time, either a single leg or both. The survival rate was greater than $95 \%$.

\section{Cultures}

Cells were plated on collagen-coated coverslips that formed the bottom of a 1-2 cm hole cut in the bottom of a $35 \mathrm{~mm}$ Falcon tissue culture dish. The coverslip was sealed in place with silicone adhesive. Standard medium for neurons and muscle cultures consisted of Eagle's Minimum Essential Medium (MEM) supplemented with glutamine (2.4 mM), heatinactivated horse serum $(10 \% \mathrm{vol} / \mathrm{vol})$, conalbumin $(0.04 \mathrm{mg} / \mathrm{ml}$; Sigma, Type II), penicillin (50 units $/ \mathrm{ml})$, and streptomycin $(50 \mu \mathrm{g} / \mathrm{ml})$. In some experiments, conalbumin was omitted, and the medium was supplemented with a saline extract of macerated chick embryos $(5 \% \mathrm{vol} / \mathrm{vol})$.

\section{Spinal cord}

The lumbar regions of spinal cords ipsilateral to injected limbs were dissected into an ice-cold $\mathrm{Ca}^{2+}, \mathrm{Mg}^{2+}$ free balanced salt solution and the meninges peeled away. Minced cord fragments were then incubated with $0.01 \mathrm{mg} / \mathrm{ml}$ trypsin (Sigma, Type VII) for $20 \mathrm{~min}$ at $37^{\circ} \mathrm{C}$, centrifuged, resuspended in culture medium, and triturated with a narrowed Pasteur pipette. Cells were counted in a hemocytometer, and $3 \times 10^{5}$ cells were added to each well created by the glass coverslip in $300 \mu \mathrm{l}$ of medium. After $24 \mathrm{hr}$, an additional $1 \mathrm{ml}$ of medium was added to each culture, and the cultures were fed again on day 4 . Spinal cord cells were cultured on a variety of substrates: dried films of collagen (Bornstein, 1958) or polylysine (Sigma) or intact myotubes grown as described below.

\section{Muscle}

Mononucleated myogenic cells were dissociated from pectoral muscles of $11 \mathrm{~d}$ embryos and plated as previously described (Fischbach, 1972). After $3 \mathrm{~d}$, cytosine arabinoside (ara $\mathrm{C}$ ) was added to the medium for $48 \mathrm{hr}$ to eliminate dividing fibroblasts. Neurons were added on day 5. Muscle conditioned medium was prepared by adding fresh medium to myotube cultures for $48 \mathrm{hr}$ beginning on day 5. Muscle conditioned medium was centrifuged at $800 \times g$ for $10 \mathrm{~min}$ and diluted $1: 1$ with fresh medium.

\section{Cell sorting}

In each experiment 10-20 spinal cords from chicks injected with fluorescein-WGA were dissociated as described above, except that, after 20 min of trypsinization, fetal calf serum (Gibco) was added to the salt solution to a final concentration of $20 \%$ to inhibit the enzyme. Cord fragments were then triturated and centrifuged at $800 \times g$ for $10 \mathrm{~min}$. The cell pellet was resuspended in a serum-free salt solution (described below) and filtered through a double layer of lens paper to remove clumps. The sample was then placed on ice. Cells were sorted in a Becton-Dickinson fluorescence-activated cell sorter (FACS IV) equipped with a $2 \mathrm{~W}$ argon laser (Spectra Physics, 164-46) set to deliver $120 \mathrm{~mW}$ of power at $488 \mathrm{~nm}$. Emission spectra of the excited cells were bandpassfiltered between 520 and $560 \mathrm{~nm}$. The sheath fluid pressure was $13.5-$ $14.0 \mathrm{psi}$, and the flow rate was adjusted so that cells passed through the $70 \mu \mathrm{m}$ nozzle aperture at a rate of $2000 / \mathrm{sec}$. For long-term culture after cell sorting, one must pay strict attention to sterility. Therefore, the lines were flushed with 5\% Clorox and 70\% ethanol, and all filters were changed before each run.

Prior to each sorting, a small sample of cells $(50,000)$ was analyzed for size (forward light scatter) and fluorescence intensity. This analysis always revealed a discrete subpopulation of fluorescent cells (see $\mathrm{Re}$ sults). The sorting windows were then set to ensure maximum purity of motoneurons, sacrificing some yicld, and the entirc population of dissociated cells was sorted into a $3 \mathrm{ml}$ conical tube containing $1 \mathrm{ml}$ of complete medium. The cells were centrifuged for $10 \mathrm{~min}$ at $800 \times \mathrm{g}$, resuspended, counted, and plated at a concentration of 100,000 cells/ $\mathrm{ml}$ in $50-150 \mu \mathrm{l}$ medium, depending on the size of the wells.

\section{Fluorescence microscopy}

The number of fluorescent neurons present in heterogeneous (unsorted) spinal cord cell cultures was counted on the stage of a microscope equipped with inverted epifluorescence optics. The cells were illuminated with a $100 \mathrm{~W}$ mercury bulb filtered between 350 and $460 \mathrm{~nm}$ and viewed through a $515 \mathrm{~nm}$ barrier filter. Nearly 100 visual fields were examined in each culture using a $40 \times$ phase-contrast, oil-immersion objective (N.A. 1.3), and $6.3 \times$ eyepieces. In the same cultures, the total number of neurons was counted in 20 visual fields. Cultures of sorted neurons were examined $24 \mathrm{hr}$ after plating to determine the percentage of cells that contained fluorescent granules. Every day thereafter the total number of neurons present in sister cultures was determined by examining 16 visual fields ( $20 \times$ phase-contrast objective).

\section{Frozen sections}

Embryos were eviscerated and the vertebral canal and adjacent dorsal root ganglia were dissected out and placed in cold $4 \%$ formaldehyde in $0.1 \mathrm{~m}$ phosphate buffer, $\mathrm{pH} 7.4$, for $3 \mathrm{hr}$. After fixation, the tissue was immersed in $30 \%$ sucrose in $0.1 \mathrm{M}$ phosphate buffer overnight. Frozen sections were cut at $15 \mu \mathrm{m}$ on an SLEE cryostat, dehydrated, and mounted in Protexx (Scientific Products). Sections were viewed and photo- 


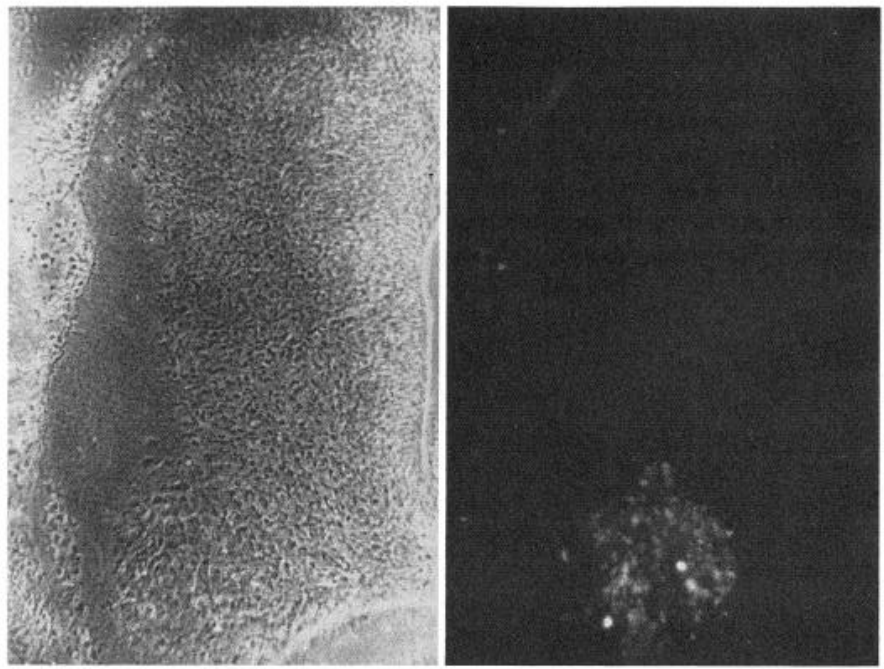

Figure 1. Lateral motor column neurons labeled via retrograde transport of fluorescent tracers. A $15 \mu \mathrm{m}$ frozen section cut from the lumbar spinal cord of a $6 \mathrm{~d}$ chick embryo whose right leg had been injected 16 hr previously with a combination of LY-VS and LY-WGA (see Materials and Methods). Only half of the spinal cord is shown. Lateral, left; medial, right. Left, phase contrast; Right, fluorescence. $\times 100$.

graphed under phase-contrast and epifluorescence illumination using a $16 \times, 0.5$ N.A. objective.

\section{GABA autoradiography}

Cultures were incubated with $0.1 \mu \mathrm{m}{ }^{3} \mathrm{H}-\mathrm{GABA}$ (New England Nuclear; specific activity, $34.7 \mathrm{Ci} / \mathrm{mmol}$ ) for $45 \mathrm{~min}$ at $37^{\circ} \mathrm{C}$ in Hank's Balanced Salt Solution (BSS), washed for $10 \mathrm{~min}$ in $10 \mathrm{ml}$ ice-cold BSS, and fixed in $1.6 \%$ glutaraldehyde buffered with $0.2 \mathrm{~m}$ sodium cacodylate at $\mathrm{pH}$ 7.4 for $10 \mathrm{~min}$ at $4^{\circ} \mathrm{C}$ and $60 \mathrm{~min}$ at room temperature. The dishes were rinsed for $1 \mathrm{hr}$ in distilled water, dried, and dipped in Kodak NTB-3 emulsion diluted 1:1 with water and warmed to $41^{\circ} \mathrm{C}$. After $24 \mathrm{hr}$ in a lighttight dessicated box at room temperature, the emulsion was developed in Kodak D-19 developer, fixed in Kodak Rapidfix, and rinsed with water. The number of GABA-positive cells in each culture was counted by examining 10 visual fields/culture using a $20 \times$ objective.

\section{Electrophysiology}

A Dagan 8900 patch-clamp amplifier equipped with a $10^{10} \Omega$ feedback resistor was used to record from motoneurons in both voltage- and current-clamp modes. Microelectrodes used for whole-cell recording were pulled in 2 stages and filled with a solution containing $\mathrm{KCl}(140$ $\mathrm{mm}), \mathrm{MgCl}_{2}$ (2 mM), EGTA-KOH (11 mM), $\mathrm{CaCl}_{2}$ (1 mM), HEPES (10 $\mathrm{mM}), \mathrm{pH}$ 7.4. The cells were bathed in a serum-free salt solution containing $\mathrm{NaCl}(120 \mathrm{~mm}), \mathrm{KCl}(5.4 \mathrm{~mm}), \mathrm{NaH}_{2} \mathrm{PO}_{4}(0.8 \mathrm{~mm}), \mathrm{CaCl}_{2}(3.6$ $\mathrm{mm}), \mathrm{MgCl}_{2}(0.16 \mathrm{~mm}), \mathrm{MgSO}_{4}(0.64 \mathrm{~mm})$, glucose $(6 \mathrm{~mm})$, and HEPES $(12 \mathrm{~mm}), \mathrm{pH} 7.4$. All recordings were made at room temperature $\left(\sim 24^{\circ} \mathrm{C}\right)$ with patch-clamp electrodes.

\section{Dye injection and morphologic analysis}

The morphology of several motoneurons was determined after injecting them with LY CH. Fine-tipped microelectrodes were filled with $4 \%$ LY $\mathrm{CH}$ (Aldrich) in $0.25 \mathrm{M} \mathrm{LiCl}_{2}$, and the dye was injected with 1-sec-long $0.25-0.5 \mathrm{nA}$ hyperpolarizing pulses repeated at $0.5 \mathrm{~Hz}$ for $5 \mathrm{~min}$. Fluorescent cells and neurites were viewed with an SIT camera (Dage MTI 65 series) connected to a high-resolution TV monitor (Audiotronics 947) and a videotape recorder (Panasonic NV-8030). Tracings of the neuritic arbor prepared from the videotapes were analyzed by hand or with the aid of a digitizing tablet (GTCO).

\section{Results}

\section{Labeled motoneurons}

The photomicrograph in Figure 1 shows a frozen section cut through the lumbar spinal cord of a $6 \mathrm{~d}$ chick embryo whose

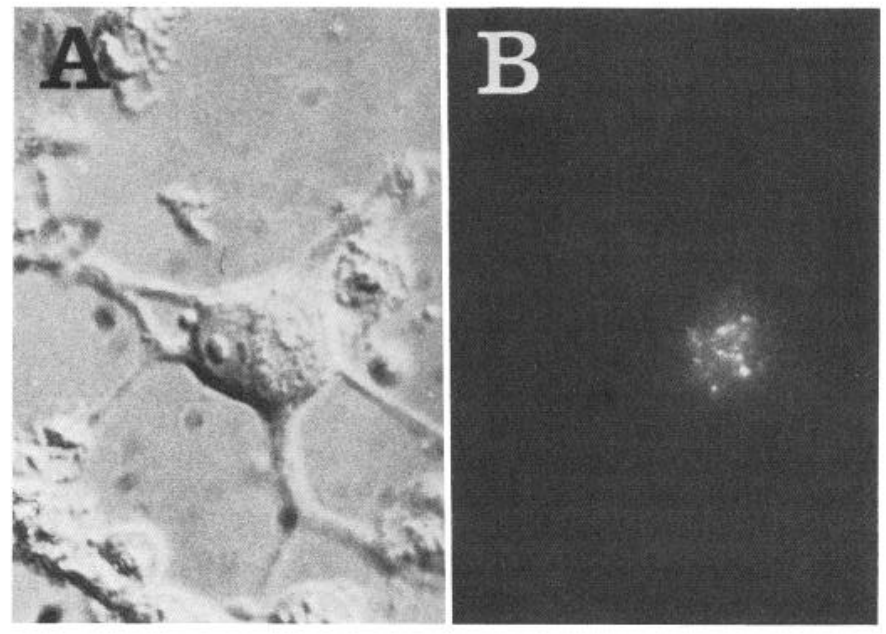

Figure 2. An identified motoneuron. Interference contrast $(A)$ and fluorescence $(B)$ views of a dissociated labeled motoneuron located 24 $\mathrm{hr}$ after plating. The chick embryo from which this cell was obtained had been injected with a combination of LY-VS and LY-WGA conjugates, as described in Materials and Methods. Note the speckled appearance of the fluorescence in $B$, which indicates that the tracer was confined to granules within the cytoplasm.

leg had been injected $15 \mathrm{hr}$ earlier with LY-VS plus LY-VS conjugated to WGA (LY-WGA). Fluorescence was confined to cells located in the lateral motor column. [The vinyl sulfone form of LY reacts with amino acid and sulfydryl groups at neutral $\mathrm{pH}$, so it is probably transported coupled to axonal proteins (Stewart, 1981).] Indeed, spinal cords sectioned as long as $3 \mathrm{~d}$ after injection showed that the label remained restricted to the ipsilateral motor column. Similar results were obtained when limbs were injected with LY-VS alone or with Fl-WGA.

The choice of fluorescent tracer depended on the experiment. Although injections of LY-VS alone or LY-WGA conjugates labeled motoneurons, the brightest fluorescence was observed when a combination of the two was used. A combination of FITC plus Fl-WGA was tried but proved unsatisfactory, as fluorescence was distributed diffusely throughout the ventral and dorsal horns of the cord. Motoneurons labeled with Fl-WGA alone were usually less bright then neurons labeled with the Lucifer Yellow combination. However, Fl-WGA was markedly superior for experiments involving cell sorting, as discussed below.

\section{Survival of motoneurons in heterogeneous spinal cord cell cultures}

When spinal cords dissected from embryos previously injected with LY plus LY-WGA were dissociated and plated on collagencoated glass coverslips containing multinucleated myotubes, a small percentage of the neurons contained brightly fluorescent granules in their cytoplasm (Fig. 2). The fluorescent cells were among the largest in the cultures (10-12 $\mu \mathrm{m})$, and by $24 \mathrm{hr}$ after plating they were invariably multipolar. During the course of experiments in which LY CH was injected into identified neurons to visualize their dendrite arbors (see below), we noted that about $25 \%$ were dye coupled to nearby neurons (see O'Brien and Fischbach, 1986b; Fig. 4). This raised the possibility that LY-VS or a metabolite might be transferred between cells in vitro as well. However, following retrograde transport of the dye, fluorescence was never distributed diffusely throughout the cytoplasm, and we never observed a grouping of lightly fluorescent cells around a more heavily stained one. Therefore, we conclude that all labeled cells in culture were derived from the 


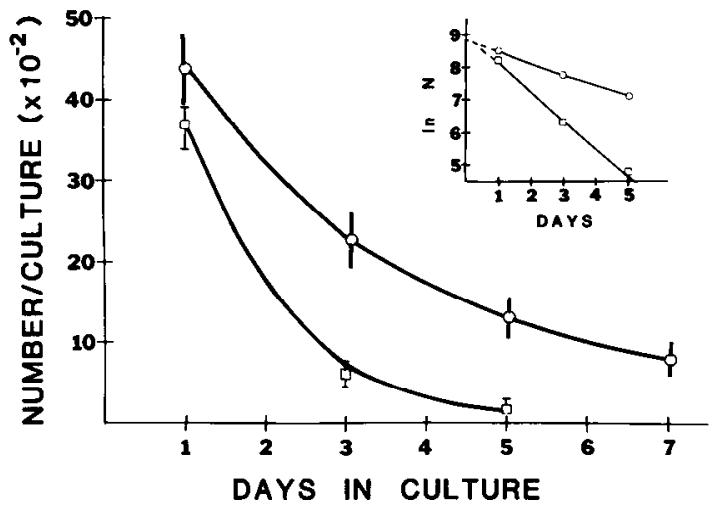

Figure 3. Effect of skeletal muscle on the number of fluorescent cells in heterogeneous spinal cord cultures. Spinal cord cells, $3 \times 10^{5}$, including LY-labeled motoneurons, were plated on 1-cm-diameter collagen-coated glass coverslips in the presence (circles) or absence (squares) of skeletal muscle. The medium did not contain embryo extract. The number of fluorescent cells present in each culture was determined as described in Matcrials and Methods. Each point represents the mcan \pm SEM of at least 4 cultures from 4 different platings. Inset, Same data plotted on a logarithmic ordinate.

lateral motor column, and we shall use the terms "fluorescent cells" and "motoneurons" interchangeably.

The number of fluorescent cells observed in heterogeneous spinal cord-muscle cocultures decreased with a half-life of approximately $2 \mathrm{~d}$ (Fig. 3, upper curve). Extrapolation of the exponential curve back to $t=0$ indicates that, on average, at least 6500 labeled cells were added to each dish. Since 300,000 spinal cord cells were added to each culture, motoneurons make up about $2 \%$ of the population that survived dissociation.

The decline in number of fluorescent cells might be due to a loss of cells or to a loss of fluorescence within each cell. To examine this issue, motoneurons were identified by fluorescence microscopy on day 1,3 , or 5 after plating, photographed under low-power phase-contrast illumination, and then relocated 48 $\mathrm{hr}$ later. If the exponential decline in the number of fluorescent cells is due to cell death, then only $50 \%$ of the cells identified on a given day should be alive $2 \mathrm{~d}$ later. In fact, we found that $91 \%(n=21)$ of the motoneurons were alive $2 \mathrm{~d}$ after initial identification. Approximately $30 \%$ of the photographed fields could not be relocated unambiguously. These data indicate that the curve in Figure 3 reflects loss of fluorescence and that in the presence of skelctal muscle the amount of motoncuron ccll death during the first week in culture is quite small.

When plated on collagen in the absence of myotubes, the number of fluorescent cells declined more precipitously (Fig. 3, lower curve), so that by day 5 only $20 \%$ as many motoneurons were visualized compared with cultures grown with skeletal

Table 1. Neuron survival in heterogeneous spinal cord cultures

\begin{tabular}{lcc} 
& \multicolumn{2}{c}{ Cells/culture $\left(\times 10^{-2}\right)$} \\
\cline { 2 - 3 } Sample & Collagen & Muscle \\
\hline Fluorescent cells (motoneurons) & $1.7 \pm 1$ & $10.9 \pm 1.1$ \\
GABA-labeled neurons & $291 \pm 20$ & $240 \pm 40$ \\
Total & $1200 \pm 240$ & $1290 \pm 240$
\end{tabular}

Spinal cord cells including labeled motoneurons were plated on collagen or muscle in standard medium ( $0 \% \mathrm{CEE})$. The total number of neurons, the number of fluorescent motoneurons, and the number of neurons that accumulated ${ }^{3} \mathrm{H}-\mathrm{GABA}$ were determined on day 5 in vitro as described in Materials and Methods. Each entry represents the mean \pm SD of at least 4 cultures from 4 different platings.

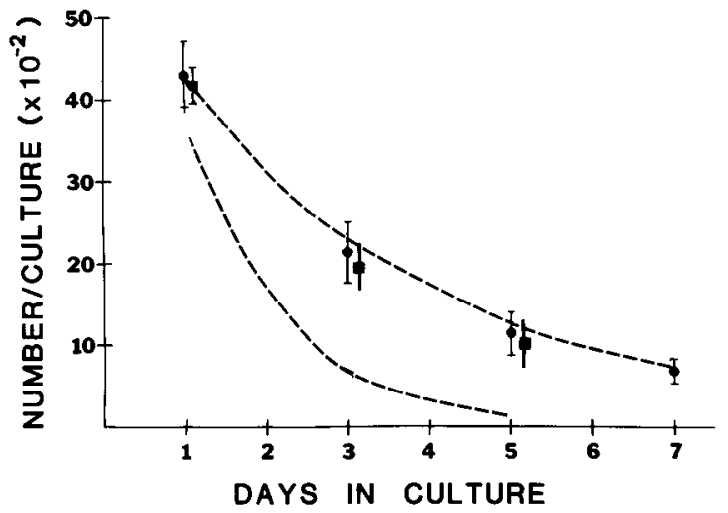

Figure 4. Effect of chick embryo extract (CEE) and muscle conditioned medium on the number of fluorescent cells in mixed spinal cord cultures. Spinal cord cells containing labeled motoneurons were cultured on collagen-coated glass coverslips in medium containing 5\% CEE (squares) or muscle conditioned medium (circles). Each point represents the mean number of fluorescent cells/culture \pm SEM of 4 cultures from 4 separate platings. The number of fluorescent cells (motoneurons) observed with time in skeletal muscle cocultures (upper dotted line) or in the absence of CEE and muscle (lower dotted line) is shown for comparison (see Fig. 3).

muscle. Relocation studies showed that the decline in number of fluorescent cells was due to cell death rather than to an acceleration of fluorescence fading; only $21 \%(n=19)$ of the motoneurons identified on a given day survived an additional $2 \mathrm{~d}$ in the absence of muscle.

Spinal cord interneurons (unlabeled cells) appeared to be more hardy than motoneurons in that their survival did not depend on the presence of skeletal muscle (Table 1). The number of neurons plated on collagen decreased by only $23 \%$ after $5 \mathrm{~d}$ (not statistically significant). We also examined a subset of the interneuron pool that was labeled by high-aflinity uptake of ${ }^{3} \mathbf{H}-$ GABA. After $5 \mathrm{~d}$ in culture, the number of these presumptive inhibitory interneurons identified by autoradiography was the same in cultures grown with and without muscle (Table 1).

Direct contact with myotubes was not necessary for the survival of dissociated motoneurons. Chick embryo extract ( $5 \%$ $\mathrm{vol} / \mathrm{vol}$ ) and muscle conditioned medium (diluted 1:1 with fresh medium and replaced each day) also enhanced the survival of motoneurons plated on collagen (Fig. 4). The number of fluorescent cells was similar to the number in cultures grown in the presence of skeletal muscle throughout the first week after plating (upper dashed line). Relocation studies of motoneurons grown with either CEE or muscle conditioned medium showed that $93 \%(n=29)$ were alive $2 \mathrm{~d}$ after initial identification.

\section{Survival of motoneurons in the absence of interneurans and glia}

The ability to label motoneurons with fluorescent tracers allowed us not only to identifiy motoneurons in heterogeneous spinal cord cultures but also to sort them away from spinal cord interneurons and non-neuronal cells. Figure 5 shows typical analyses of spinal cord cells dissociated from chicks previously injected with Fl-WGA. The major peak, extending up to channel 10 in Figure $5 A$, reflects the autofluorescence of spinal cord cells. The small peak, channel 10-100, was present only in injected chicks (Fig. 5A, lower panel) and thus most likely represents the motoneuron population. This clear separation of the 2 peaks was the rule when Fl-WGA-labeled cells were probed with the $488 \mathrm{~nm}$ beam of the argon laser at relatively low intensity (120 $\mathrm{mW}$ ). We did not obtain comparable separations when LY-WGA-labeled cells were screened with a $458 \mathrm{~nm}$ beam even when higher intensities were used. The maximum absorbance 

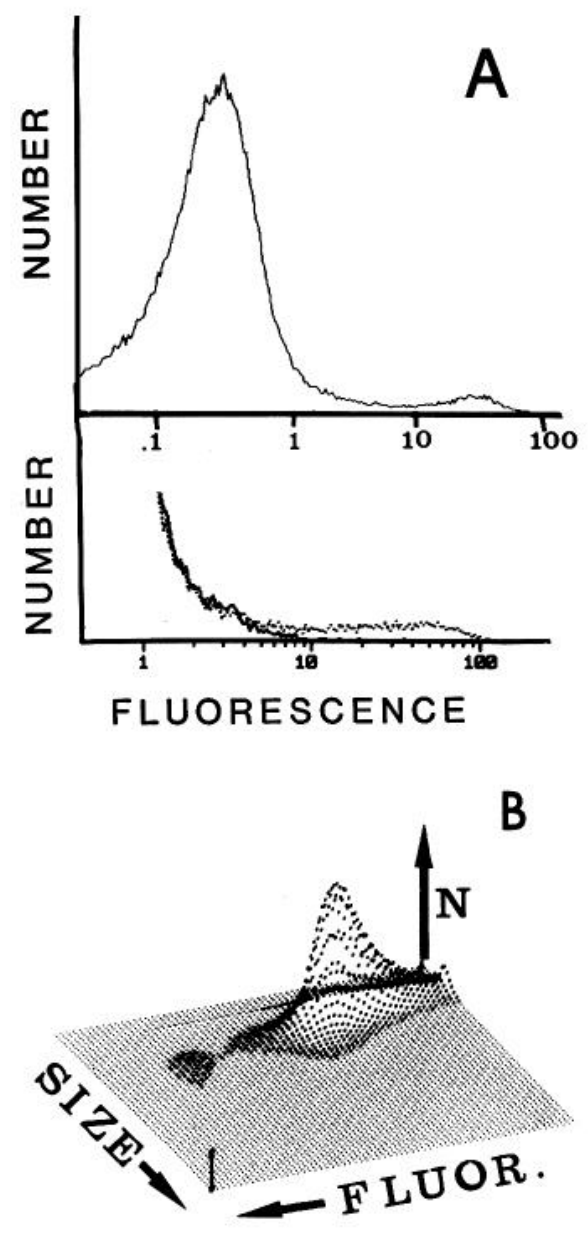

Figure 5. Fluorescence-activated cell sorter (FACS IV) analysis of spinal cord cells containing labeled motoneurons. Spinal cord cells were dissociated from $6 \mathrm{~d}$ chick embryos injected $16 \mathrm{hr}$ earlier with Fl-WGA. $A$, Fluorescence, in arbitrary units, is shown on a log scale along the abscissa. The vast majority of cells were included within the initial 10 fluorescence units. A subpopulation of brightly fluorescent cells fell between 10 and 100 fluorescence units. The lower panel shows that the intensely fluorescent subpopulation (dotted line) is absent from uninjected chicks (continuous line). B, Three-dimensional plot from another sorting emphasizes the excellent separation of the intensely fluorescent cells from the main population.

of LY $(430 \mathrm{~nm})$ is quite distant from the $458 \mathrm{~nm}$ line, the nearest wavelength emitted by the argon laser, and the increased intensity required to excite the dye resulted in a large increase in nonspecific autofluorescence that blurred the distinction between labeled and unlabeled cells. The $488 \mathrm{~nm}$ line of the laser, however, coincides perfectly with the peak absorbance of fluorescein.

For most sortings, we labeled 20 lumbar hemicords and obtained about $8 \times 10^{6}$ cells following dissociation and filtration. The discrete peak of highly fluorescent cells contained $1.5-2.0 \%$ of the starting population, or about $10^{5}$ cells. This agrees closely with our estimate of the percentage of motoneurons based on counts of LY-labeled cells in heterogeneous cultures. To maximize the purity of the motoneuron pool, we collected only the brightest $70 \%$ of the intensely fluorescent cells. Between 50,000 and 60,000 cells were recovered following centrifugation and resuspension, $85 \%$ of which excluded trypan blue. When these cells were added to cultures containing skeletal myotubes, the plating efficiency, defined as the ratio of the number of neurons counted in culture on day 1 to the number of viable neurons plated, ranged between 40 and $60 \%$.

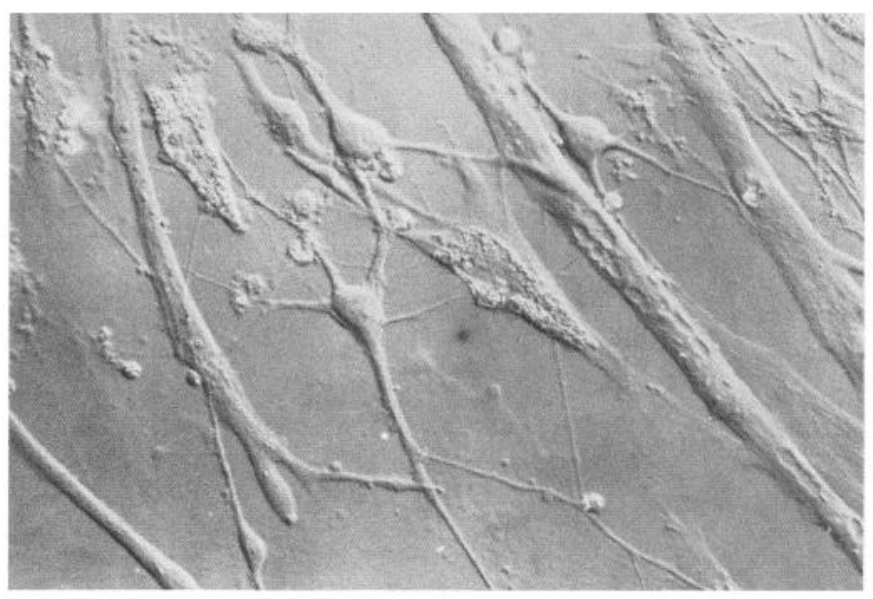

Figure 6. Interference contrast micrograph of 3 sorted motoneurons a week after plating on a myotube-containing coverslip. About 30,000 neurons were added to the culture.

One day after plating, $90-95 \%$ of the neurons in cultures seeded with sorted cells contained brightly fluorescent granules. Therefore, the survival of sorted motoneurons was assessed by simply counting the number of neurons at various times after plating. When sorted motoneurons were cultured with skeletal muscle, they appeared healthy (Fig. 6), and their number remained constant during the first week in vitro (Fig. 7). Although sorted motoneurons could be grown for $7 \mathrm{~d}$ in the presence of myotubes without loss in number, they deteriorated at later times. We did not follow this decline each day, but by $14 \mathrm{~d}$ after plating no neurons remained.

When sorted cells were plated on collagen in standard medium, none was present $24 \mathrm{hr}$ later. Either they did not attach or they degenerated rapidly. Sorted cells attached to polylysinecoated coverslips, but in the absence of myotubes few survived longer than $2 \mathrm{~d}$ (Fig. 7). Muscle conditioned medium and embryo extract prolonged the survival of sorted motoneurons plated on polylysine (Fig. 7). However, the effect of these treatments on sorted motoneurons was not as prolonged as that of intact myotubes: The number of motoneurons began to decline between the 3rd and 4th days in vitro. In this regard, sorted motoneurons differed from motoneurons in mixed cultures.

\section{Electrophysiology}

Recordings were obtained from sorted and unsorted motoneurons grown with myotubes. The identity of each cell was con-

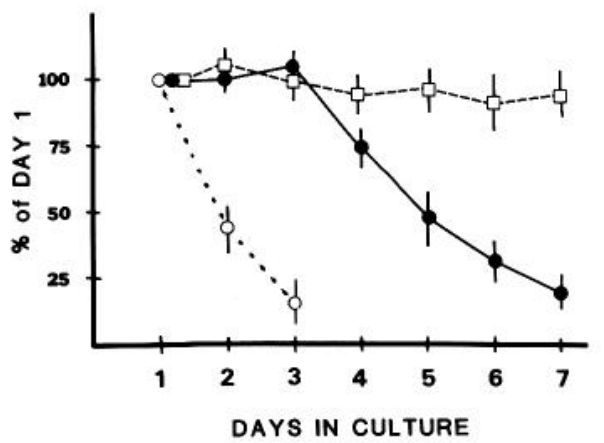

Figure 7. Survival of sorted motoneurons. Each point represents the mean \pm SD of 4 different sortings. Open squares, coculture with skeletal muscle on collagen without CEE; open circles, polylysine surface with CEE or muscle; closed circles, polylysine surface with either muscle conditioned medium or $5 \%$ CEE. (Survival under these 2 conditions was identical, so the results were pooled.) 


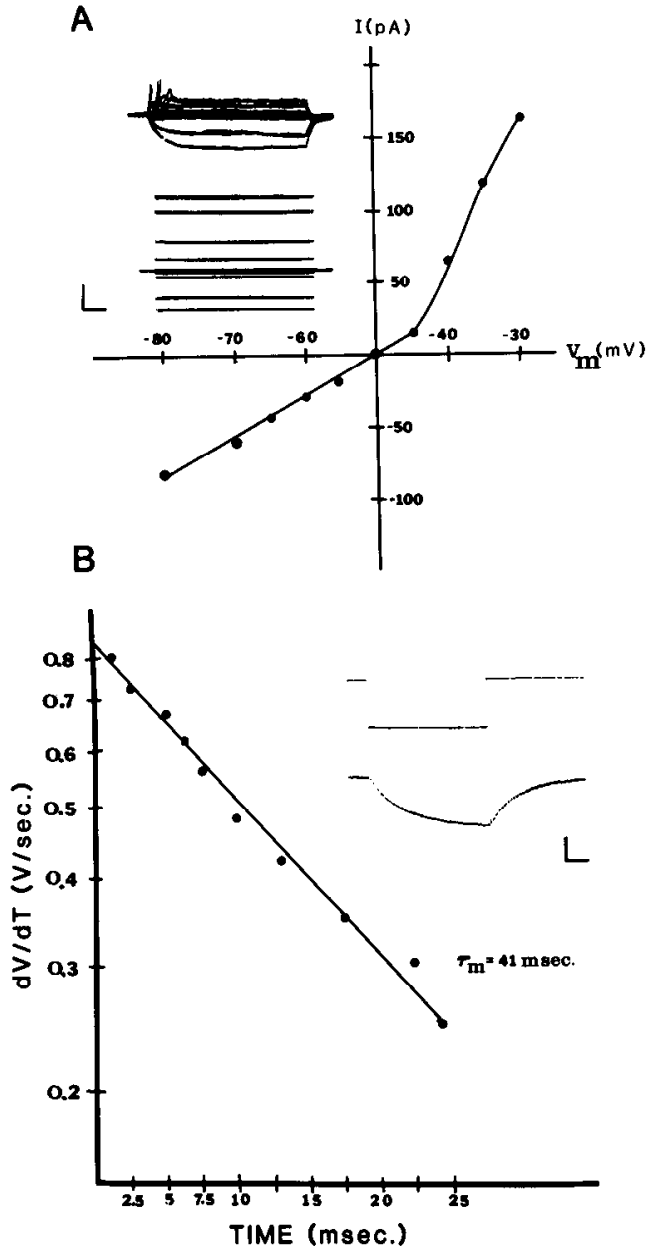

Figure 8. Electrophysiologic properties of identified motoneurons. Inset (in $A$ ) shows the voltage response (upper traces) of a motoneuron to various constant-current pulses (lower traces). Vertical bar, $20 \mathrm{mV}, 50$ $\mathrm{pA}$; horizontal bar, $100 \mathrm{msec}$. The steady-state current-voltage curve is plotted below. Inset (in $B$ ) shows a membrane-charging curve from another motoneuron on a faster time base. Vertical bar, $10 \mathrm{mV}, 50 \mathrm{pA}$; horizontal bar, $20 \mathrm{msec}$. A plot of the rate of change of the cells' membrane potential as a function of time is shown below. The negative slope of this plot is a measure of the membrane time constant.

firmed by fluorescence microscopy with exposures of $5 \mathrm{sec}$ or less. Longer exposure to exciting wavelengths resulted in deterioration of the membrane potential. Because of the gradual loss of the fluorescent tracer, unsorted motoneurons could be identified only during the first week after plating, when the cells are quite small. We could not obtain stable recordings with conventional intracellular electrodes during this interval, but Gigaseal recording methods allowed us to rccord from motoncurons as early as $1 \mathrm{~d}$ after plating.

\section{Passive properties}

No significant differences between sorted and unsorted motoneurons were noted with regard to resting membrane potential $\left(V_{\mathrm{m}}\right)$ or input resistance $\left(R_{\mathrm{in}}\right)$ (Table 2). However, the mean $V_{\mathrm{m}}$ of about $-50 \mathrm{mV}$ is about $20 \mathrm{mV}$ more positive, and the mean $R_{\text {in }}$ of about $450 \mathrm{M} \Omega$ is nearly 2 orders of magnitude greater, than values recorded in adult motoneurons in vivo. As expected, the $R_{\text {in }}$ decreased somewhat between days 4 and 6 in culture as the neurons increased in size. Steady-state current-voltage curves were constructed for 6 motoneurons, one of which is shown in Figure $8 A$. The slope resistance decreased as the membrane was depolarized by outward current pulses, but the resistance re-
Table 2. Electrophysiological parameters of cultured motoneurons

\begin{tabular}{cccccc} 
& Sorted & & & Unsorted & \\
\cline { 2 - 3 } \cline { 5 - 6 } Parameter & $\mathrm{D} 4$ & $\mathrm{D} 6$ & & $\mathrm{D} 4$ & $\mathrm{D} 6$ \\
\hline Resting potcntial & $50 \pm 2.5$ & $49 \pm 2.2$ & & $50 \pm 2.4$ & $51 \pm 2.7$ \\
$\quad(\mathrm{mV})$ & $(n=50)$ & $(n=82)$ & & $(n=80)$ & $(n=103)$ \\
Input resistance & $434 \pm 71$ & $303 \pm 59$ & & $470 \pm 46$ & $330 \pm 59$ \\
$\quad(\mathrm{M} \Omega)$ & $(n=35)$ & $(n=60)$ & & $(n=25)$ & $(n=29)$ \\
Action potential & $67 \pm 5$ & $70 \pm 5$ & $65 \pm 4$ & $69 \pm 5$ \\
$\quad(\mathrm{mV})$ & $(n=23)$ & $(n=18)$ & & $(n=19)$ & $(n=16)$ \\
Afterhyperpolar- & $86 \pm 18$ & $82 \pm 9$ & $68 \pm 8$ & $77 \pm 15$ \\
$\quad$ ization (msec) & $(n=23)$ & $(n=18)$ & & $(n=19)$ & $(n=16)$
\end{tabular}

Electrophysiological properties of identified motoneurons in sorted and unsorted cultures. Input resistance was determined by injecting small $150 \mathrm{msec}$ pulses of inward current that hyperpolarized the membrane by about $5 \mathrm{mV}$. Action potentials were initiated with brief $(2 \mathrm{msec})$ depolarizing pulses. All entries represent means \pm SD. $D$, days after plating. $n$, number of motoneurons. $T=24^{\circ} \mathrm{C}$.

mained constant during hyperpolarizing inward pulses. This represents another difference from adult motoneurons, in which inward-going rectification is the rule (Barrett et al., 1980; Nelson and Frank, 1967).

The charging curve shown in Figure $8 B$ (see Rall, 1969) recorded from a motoneuron grown in culture for $6 \mathrm{~d}$ was adequately fit by a single exponential corresponding to a membrane time constant $\left(\tau_{\mathrm{m}}\right)$ of $38 \mathrm{msec}$. Analysis of 4 other motoneurons gave a mean $\tau_{\mathrm{m}}$ of $39 \mathrm{msec}$. In no case was more than a single exponential necessary to fit the data. This surprising result represents still another difference from adult motoneurons, in which the complex dendritic arbors contribute additional (shorter) time constants (Rall, 1960, 1969). It implies that the soma and most of the dendritic tree are isopotential. We assume that this is due to a low dendritic membrane conductance at this stage of development, but the contribution of an electrode-induced shunt at the soma must be investigated further.

\section{Active properties}

A typical motoneuron action potential is illustrated in Figure $9 \mathrm{~A}$. The fast, $70 \mathrm{mV}$ spike was followed by an afterhyperpolarization of nearly $80 \mathrm{msec}$ duration. Here again, no significant differences were observed between sorted and unsorted motoneurons (Table 2).

Postspike hyperpolarizations in adult motoneurons are apparently mediated by a calcium-activated potassium current (Barrett and Barrett, 1976; Barrett et al., 1980; Krnjevic et al., 1978). In the presence of TEA, a broad hump was evident on the falling phase of evoked spikes (Fig. 9B), which presumably reflects a slow inward $\mathrm{Ca}$ current because it was eliminated by pressure ejection of a solution containing $10 \mathrm{mM} \mathrm{Co}^{2+}$ and 0.1 $\mathrm{mM} \mathrm{Ca}^{2+}$ (Fig. 9B). Nevertheless, the afterhyperpolarization of cultured chick motoneurons does not appear to be due solely to a potassium current activated by $\mathrm{Ca}^{2+}$ influx. First, it reverscd at $-64 \pm 6 \mathrm{mV}$ (mean $\pm \mathrm{SD}$ ) (Fig. 9C), compared with a calculated potassium reversal potential of $-82 \mathrm{mV}$. Second, pressure application of a solution containing $10 \mathrm{mM} \mathrm{Co}^{2+}$ and $0.1 \mathrm{mM} \mathrm{Ca}^{2+}$ resulted in only a small decrease in its amplitude $(7.3 \pm 2.8 \mathrm{mV}, n=10$, vs $10.1 \pm 2.6 \mathrm{mV}, n-18)$.

\section{Dendritic morphology}

While sorted motoneurons plated on muscle survived as well as motoneurons in heterogeneous cultures and displayed similar electrophysiologic properties, their dendritic arbors were not as extensive. Neurites of identified motoneurons were visualized following injection of LY-CH. In this series of experiments, all of the motoneurons were grown together with myotubes for 6 d. Cultures containing unsorted spinal cord cells were pulsed 


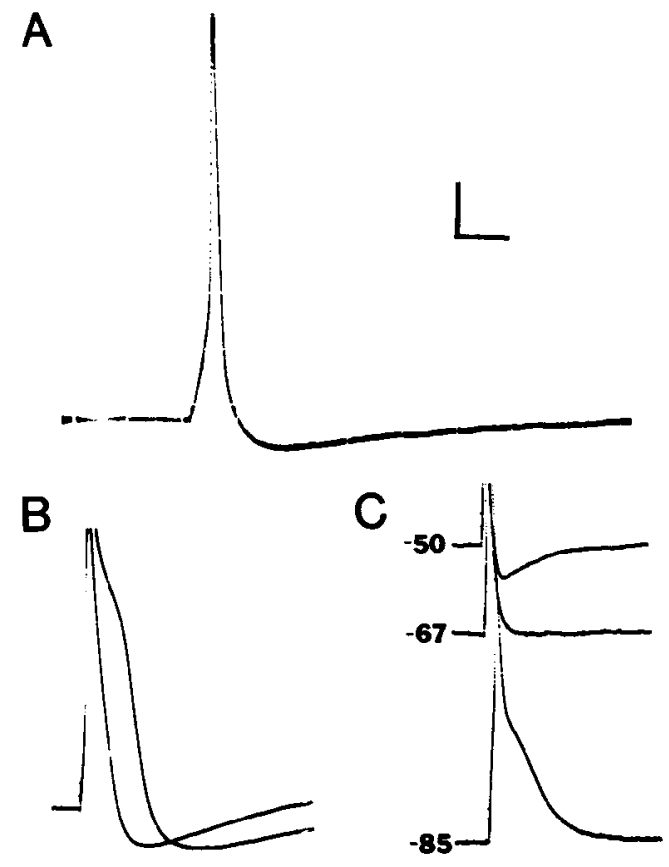

Figure 9. Action potentials of identified motoneurons. $A$, Typical brief action potential and long afterhyperpolarization. Resting potential, 52 $\mathrm{mV}$. $B$, Superimposed traces show action potentials from another motoneuron recorded in the presence of $25 \mathrm{~mm}$ TEA. Note the broad hump in the repolarizing phase. Application of $0.1 \mathrm{mM} \mathrm{Ca}^{2+}$ and $10 \mathrm{mM} \mathrm{Co}^{2+}$ along with $25 \mathrm{~mm}$ TEA eliminated the hump, but the afterhyperpolarization remained. $C$, Afterhyperpolarization from a third motoneuron is not evident at $-67 \mathrm{mV}$ and is reversed in sign at $-85 \mathrm{mV}$. Bars: 10 $\mathrm{mV}$ and $20 \mathrm{msec}$ for $A$ and $B ; 10 \mathrm{mV}$ and $50 \mathrm{msec}$ for $C$.

with ara $\mathrm{C}, 10^{-5} \mathrm{M}$, between 24 and $60 \mathrm{hr}$ in vitro to eliminate proliferating non-neuronal cells, including glia. Tracings prepared from videotapes of 2 sorted and 2 unsorted motoneurons are shown in Figure 10, and measurements made with the aid of a digitizing tablet are summarized in Table 3. Although the number of primary processes that issue directly from the perikarya was the same, the neurites of motoneurons grown alone exhibited only $65 \%$ as many branch points as the neurites of motoncurons grown with interncurons, and their total length was only $62 \%$ as great. None of the neurons, in either type of culture, exhbited a single long process that might be considered an axon.

\section{Discussion}

As previously reported (Calof and Reichardt, 1984; McPheeters and Okun, 1980; Okun, 1981), we found that fluorochromeprotein conjugates injected into the hindlimb of chick embryos are rapidly transported to the spinal cord, where they remain confined to the lateral motor column (LMC). Estimates of the recovery of dissociated motoneurons and their survival in vitro depend critically on the assumption that the label is not transferred between cells in culture. Although the fluorescent granules in cultured cells disappeared with a half-life of about $2 \mathrm{~d}$, we found no evidence of intercellular transfer. Moreover, all of the labeled cells "behave" like motoneurons in that they exhibit long-lasting postspike hyperpolarizations, and, as shown in previous experiments, they all induce clusters of $\mathrm{ACh}$ receptors on nearby contacted myotubes (Role et al., 1985).

In addition to confirming their identity, these data imply that motoneurons breed true in culture even when plated at low cell density in the absence of spinal cord interneurons or glia. The possibility is often raised that neurons may lose their identity in sparse cell culture, but that is certainly not the case here. The
Table 3. Motoneuron morphology

\begin{tabular}{llll}
$\begin{array}{l}\text { Motoneuron } \\
\text { sample }\end{array}$ & $\begin{array}{l}\text { No. of } \\
\text { primary } \\
\text { neurites }\end{array}$ & $\begin{array}{l}\text { Total neurite } \\
\text { length }(\mu \mathrm{m})\end{array}$ & $\begin{array}{l}\text { No. of } \\
\text { branch } \\
\text { points }\end{array}$ \\
\hline Sorted $(n=12)$ & $5.1 \pm 3$ & $2880 \pm 900$ & $36.1 \pm 16$ \\
Unsorted $(n=12)$ & $5.7 \pm 1.1$ & $4520 \pm 1850$ & $53.9 \pm 28$
\end{tabular}

Identified motoneurons were injected with $\mathrm{LY} \mathrm{CH}$, and videotaped images were analyzed with a digitizing tablet. Motoneurons in this series were derived from 3 separate platings (sortings). The difference in total neuritic length between sorted and unsorted cultures is significant at the $0.05 \%$ level, while the difference in branch points was significant only at the 0.1 level ( $t$ test; unpaired data with unequal variances).

resting potential and input resistance of cultured chick motoneurons were significantly different from values recorded in adult mammalian and amphibian motoneurons, and they did not exhibit inward rectification, a clear $\mathrm{Ca}^{2+}$ dependence of the postspike hyperpolarization, or multiple charging time constants. However, these deviations cannot be taken as evidence for loss of phenotype. They may represent artifacts caused by the intracellular perfusion that accompanies whole-cell recording with patch electrodes. A more interesting possibility is that they reflect the small size and immaturity of the embryonic motoneurons. Intracellular recordings from spinal cord motoneurons of $16 \mathrm{~d}$ chick embryos indicate that even at this late stage their input resistances are high $(80 \mathrm{M} \Omega)$ and they do not exhibit inward rectification (Eide et al., 1982).

Our counts of fluorescent cells in heterogeneous spinal cord cell cultures indicate that a very high percentage of the total population in the lumbar lateral motor column was labeled by LY conjugates and recovered following dissociation. We obtained about 800,000 cells from each $6 \mathrm{~d}$ lumbar hemicord, and 300,000 , or about 0.4 hemicord, were added to each culture plate. There are 17,000 motoneurons in the lumbar LMC of a $6 \mathrm{~d}$ chick embryo (Hamburger, 1975), so the maximum number possible in each culture is 6800 . Extrapolation of the curves shown in Figure 1 implies that 6500 motoneurons, or $95 \%$ of the LMC population, were labeled and alive immediately after plating. This must be considered an upper limit as the extrapolation assumes that fluorescence fades as rapidly during the first day after plating as it does at later times. The actual count of fluorescent cells $24 \mathrm{hr}$ after plating provides a lower limit estimate, and this amounts to $66 \%$ of the population. In either case the result is remarkable, considering that the motoneurons are stripped of dendrites and axons during the dissociation process. It is not without precedent, however. Comparable recoveries of embryonic ciliary ganglion neurons (Nishi and Berg, 1977) and retinal ganglion cells (McCaffery et al., 1982; Nurcombe and Bennett, 1981) have been reported with dissociation techniques that are similar to our own.

As expected, the recovery of sorted motoneurons was not as great as the recovery of unsorted motoneurons. Starting with 20 lumbar hemicords, we recovered 50,000-60,000 cells after the sorted cells were pelleted and resuspended. Recalling that only $70 \%$ of the intensely fluorescent, discrete peak was collected, this represents $21-26 \%$ of the total LMC complement. Several factors may contribute to this relatively low yield. Perhaps the most likely is that some cells are damaged by the turbulent flow through the FACS IV tubing and $70 \mu \mathrm{m}$ aperture.

When spinal cord cells were plated in cultures containing myotubes, there was no decline in the number of motoneurons during the first week in culture. The labeled but unsorted motoneurons appeared healthy under interference or phase-contrast illumination, and there was no decline in resting membrane potential or action potential amplitude. During the same interval, about $40 \%$ of the lumbar LMC neurons degenerate (Ham- 
Figure 10. Morphology of 2 sorted and 2 unsorted motoneurons located $6 \mathrm{~d}$ after plating. The cells were injected with $\mathrm{LY} \mathrm{CH}$, and their neuritic arbors were traced from a video monitor. Bar, $100 \mu \mathrm{m}$.

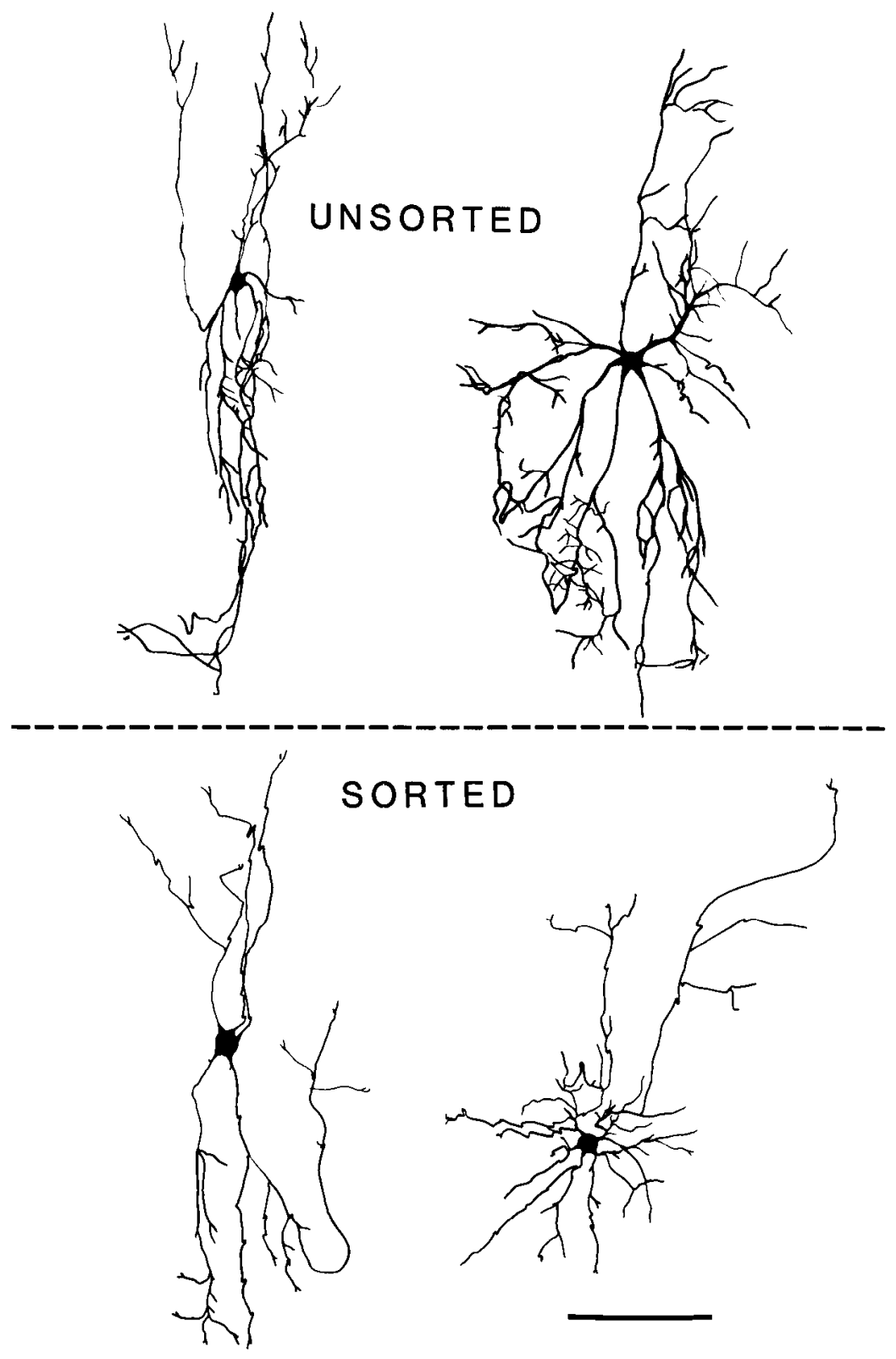

burger, 1975). Thus, it appears that uninnervated myotubes can prevent the major phase of natural cell death from occurring on schedule in vitro. An analogous result was obtained by Nishi and Berg (1977) in their studies of neurons dissociated from ciliary ganglia prior to the period of cell death. In regard to spinal cord cells, motoneurons are apparently unique in their dependence on myotubes: interneurons survive as well when plated on collagen as on muscle.

Sorted motoneurons also survived for 1 week when plated on muscle. Considering the purity of our sorted population, this suggests that the beneficial effect of myotubes is exerted directly on the motoneurons rather than indirectly on interneurons or glia. This conclusion must be tempered, however, by the fact that only about $25 \%$ of the motoneurons were recovered following sorting. We assume that cell loss at the various stages occurs at random, but the possibility that a hardy subpopulation was selected must be borne in mind. The fact that $100 \%$ of these cells die in the absence of muscle argues against this possibility.

Even when plated on muscle, sorted motoneurons degenerated during the second week in culture. It is possible that myo- tubes stop producing survival factors as they become innervated or as they age. Alternatively, it may be that target-derived factors are no longer sufficient. Recent experiments have emphasized the role of segmental and suprasegmental afferent inputs on the survival of embryonic and adult motoneurons (Davis et al., 1983; Okado and Oppenheim, 1984; see review by Cunningham, 1982). Removal of the lumbar neural crest and/or transection of the thoracic spinal cord in 2 d chick embryos resulted, 8-14 d later, in a $25-37 \%$ loss of LMC cells compared with agematched controls (Okado and Oppenheim, 1984). The time of onset and the magnitude of motoneuron degeneration depended on the degree of deafferentation. The fact that all sorted motoneurons degenerate by the end of the second week in culture may reflect the severity of their deafferentation. Heterogeneous spinal cord cell cultures that contain segmental and probably some propriospinal interneurons may be more comparable with the isolated spinal cord segments created by Okado and Oppenheim. Unfortunately, we could not identify motoneurons in heterogeneous cultures after 1 week because the fluorescent conjugates were lost and the cultures became too complex to relocate 
motoneurons identified earlier. A more permanent label (see Katz et al., 1984) would be of great value in future studies of survival in mixed spinal cord cell cultures.

The mechanism of the afferent influence on motoneuron survival may be different from that of the target. Most of the neuron loss in deafferented segments occurs after the major phase of "naturally" occurring degeneration, which is known to be influenced by target tissue (Davis et al., 1983; Okado and Oppenheim, 1984). In addition, ACh receptor antagonists that prevent the early loss of motoneurons in the chick do not affect the loss following deafferentation (Okado and Oppenheim, 1984). A role for impulse or synaptic activity in motoneuron survival was suggested in a study of cultured rat spinal cord cells (Bergey et al., 1981). When the cells were plated and grown in TTX for $30 \mathrm{~d}$, very few large (but unidentified) neurons were present, and levels of CAT were reduced. It is interesting in this regard that the first synapses formed on chick motoneurons in mixed spinal cord cultures are excitatory (O'Brien and Fischbach, $1986 \mathrm{c}$ ), so thcy arc probably morc active than sortcd motoncurons.

Several laboratories have begun to search for soluble trophic factors in muscle conditioned medium or tissue extracts (see reviews by Berg, 1984; Henderson, 1983). As reported by others (Calof and Reichardt, 1984; Eagleson and Bennett, 1983), we found that muscle conditioned medium can support the survival of sorted motoneurons plated on polylysine. The study of Calof and Reichardt (1984) is most comparable with our own, as they followed the survival of sorted cells for $6 \mathrm{~d}$ after plating. At least 2 factors are required: one that attaches to the substrate and promotes process outgrowth and one that remains in solution that is required for survival beyond $24-48 \mathrm{hr}$ (Calof and Reichardt, 1984; Lander et al., 1985). We found that muscle conditioned medium was not as effective as intact myotubes: The number of motoneurons declined rapidly after $3 \mathrm{~d}$ even though the muscle conditioned medium was replaced each day (Fig. 4; see Calof and Reichardt, 1984). Nerve-muscle contact and perhaps synapse formation may provide something that is missing or present in low concentration in conditioned medium and tissue extracts. Alternatively, as noted above, non-target-derived factors may be essential. No loss of motoneurons in mixed spinal cord cell cultures grown with muscle conditioned medium was detected during the first week after plating. Thus, heterogeneous cultures may provide a more relevant or realistic assay for target-derived factors.

The processes of sorted motoneurons were not as long as those of motoneurons in mixed spinal cord cell cultures, and their branching pattern was less complex. The fact that partial or complete deafferentation can lead to atrophy and loss of dendrites has been demonstrated in a variety of neurons (Caceres and Steward, 1983; Deitch and Rubel, 1984; Hubel et al., 1977; Larsell, 1931; Levi-Montalcini, 1949; Van der Loos and Woolsey, 1973), including spinal cord motoneurons (Bernstein and Standler, 1983). Thus, interneurons may affect the form as well as the survival of their target motoneurons in vitro. We have found that interneurons influence the sensitivity of motoneuron neurites to glutamate as well as their geometry (O'Brien and Fischbach, 1985c).

\section{References}

Armson, P. F., and M. R. Bennett (1983) Neonatal retinal ganglion cell cultures of high purity: Effect of superior colliculus on thcir survival. Neurosci. Lett. 38: 181-186.

Barrett, E. F., and J. N. Barrett (1976) Separation of two voltage sensitive potassium currents and demonstration of a tetrodotoxin resistant calcium current in frog motoneurons. J. Physiol. (Lond.) 255: 737-774.

Barrett, E. F., J. N. Barrett, and W. E. Crill (1980) Voltage sensitive outward currents in cat motoneurons. J. Physiol. (Lond.) 304: 251276.
Berg, D. K. (1984) New neuronal growth factors. Annu. Rev. Neurosci. 7: $149-170$.

Berg, D., and G. D. Fischbach (1978) Enrichment of spinal cord cell cultures with motoneurons. J. Cell Biol. 77: 83-98.

Bergey, G. K., S. C. Fitzgerald, B. K. Schrier, and P. G. Nelson (1981) Neuronal maturation in mammalian cell culture is dependent on spontaneous electrical activity. Brain Res. 207: 49-58.

Bernstein, J. J., and N. A. Standler (1983) Dendritic alteration of rat spinal motoneurons after dorsal mince: Computer reconstruction of dendritic fields. Exp. Neurol. 82: 532-540.

Bornstein, M. (1958) Reconstituted rat tail collagen used as a substrate for tissue cultures on coverslips in Maxinow slides and roller tubes. Lab. Invest. 7: 134-141.

Burke, R. E., and P. Rudomin (1977) Spinal neurons and synapses. In Handbook of Physiology, The Nervous System, Vol. 1., E. Kandel, ed., pp. 719-774, American Physiological Society, Bethesda, MD.

Caceres, A., and O. Steward (1983) Dendritic reorganization in the denervated dentate gyrus of the rat following entorhinal cortical lesions: A Golgi and electron microscopic analysis. J. Comp. Neurol. 214: 387-403.

Calof, A. L., and L. F. Rcichardt (1984) Motoncurons purificd by ccll sorting respond to two distinct activities in myotube conditioned media. Dev. Biol. 106: 194-210.

Chu-Wang, I. W., and R. W. Oppenheim (1978) Cell death of motoneurons in the chick embryo spinal cord. II. A quantitative and qualitative analysis of degeneration in the ventral including evidence for axon outgrowth and limb innervation prior to cell death. J. Comp. Neurol. 177: 59-86.

Cunningham, T. J. (1982) Naturally occurring neuron death and its regulation by developing neural pathways. Int. Rev. Cytol. 74: 163186.

Davis, M. R., M. Constantine-Paton, and D. Schorr (1983) Dorsal root ganglion removal in Rana pipiens produces fewer motoneurons. Brain Res. 265: 283-288.

Deitch, J. S., and E. W. Rubel (1984) Afferent influences on brain stem auditory nuclei in the chicken: Time courses and specificity of dendritic atrophy following deafferentation. J. Comp. Neurol. 229: 66-79.

Eagleson, K. L., and M. R. Bennett (1983) Survival of purified motoneurons in vitro: Effects of skeletal muscle-conditioned medium. Neurosci. Lett. 38: 187-192.

Eide, A. L., J. K. S. Jansen, and R. R. Ribchester (1982) The effect of lesions in the neural crest on the formation of synaptic connections in the embryonic chick spinal cord. J. Physiol. (Lond.) 324: 453-478.

Fischbach, G. (1972) Synapse formation between dissociated nerve and muscle cells in low density cell cultures. Dev. Biol. 28: 407-429.

Fischbach, G. D., and P. G. Nelson (1977) Cell culture in neurobiology. In Handbook of Physiology, The Nervous System Vol. 1., E. Kandel, ed., pp. 719-774, American Physiological Society, Bethesda, MD.

Hamburger, V. (1948) The mitotic patterns in the spinal cord of the chick embryo and their relation to histogenetic processes. J. Comp. Neurol. 88: 221-284.

Hamburger, V. (1958) Regression versus peripheral control of differentiation in motor hypoplasia. Am. J. Anat. 102: 365-402.

Hamburger, V. (1975) Cell death in the development of the lateral motor column of the chick embryo. J. Comp. Neurol. 160: 535-546.

Henderson, C. E. (1983) Roles for retrograde factors in synapse formation at the nerve-muscle junction. Prog. Brain Res. 58: 369-373.

Hollyday, M., and V. Hamburger (1976) Reduction of the naturally occurring motoneuron loss by enlargement of the periphery. J. Comp. Neurol. 170: 311-320.

Hollyday, M., and V. Hamburger (1977) An autoradiographic study of the formation of the lateral motor column in the chick embryo. Brain Res. 132: 197-208.

Hubel, D. H., T. N. Wiesel, and S. LeVay (1977) Plasticity of ocular dominance columns in the monkey striate cortex. Phil. Trans. R. Soc. Lond. [Biol.] 278: 377-409.

Huettner, J. E., and R. W. Baughman (1984) Dissociated cell cultures prepared from the visual cortex of postnatal hooded rats. Soc. Neurosci. Abstr. 10: 165.

Katz, L. C., A. Burkhalter, and W. J. Dreyer (1984) Fluorescent latex microspheres: A retrograde neuronal marker for in vivo and in vitro studies of the cortex. Nature 310: 498-500.

Krnjevic, K., E. Puil, and R. Werman (1978) EGTA and motoneuronal afterpotentials. J. Physiol. (Lond.) 275: 199-223. 
Lander, A., D. K. Fuji, and L. F. Reichardt (1985) Laminin is associated with the "neurite outgrowth-promoting factors" found in conditioned medium. Proc. Natl. Acad. Sci. USA 82: 2183-2187.

Landmesser, L. (1978) The development of motor projection patterns in the chick hind limb. J. Physiol. (Lond.) 284: 391-414.

Larsell, O. (1931) The effect of experimental excision of one eye on the development of the optic lobe and opticus layer in larvae of the tree frog (Hyla regilla). II. The effect on cell site and process growth. J. Exp. Zool. 58: 1-20.

Leifer, D., S. A. Lipton, C. J. Barnstable, and R. H. Masland (1984) Monoclonal antibody to thy- 1 enhances regeneration of processes by rat retinal ganglion cells in culture. Science 224: 303-306.

Levi-Montalcini, R. (1949) The development of the acousticovestibular centers in the chick embryo in the absence of afferent root fiber and of descending fiber tracts. J. Comp. Neurol. 91: 209-241.

Masuko, S., H. Kuromi, and Y. Shimado (1974) Isolation and culture of motoneurons from embryonic chicken spinal cords. Proc. Natl. Acad. Sci. USA 76: 3536-3541.

McCaffery, C. A., M. R. Bennett, and B. Deeher (1982) The survival of neonatal rat retinal ganglion cells in vitro is enhanced in the presence of appropriate parts of the brain. Exp. Cell Res. 48: 377-386.

McPheeters, M., and L. M. Okun (1980) Identification and isolation in vitro of presumptive motoneurons marked by retrograde transport of a new fluorescent tracer. Soc. Neurosci. Abstr. 6: 247.

Nelson, P. G., and K. Frank (1967) Anomalous rectification in cat spinal motoneurons and effect of polarizing currents on excitatory postsynaptic potential. J. Neurophysiol. 30: 1097-1113.

Nishi, R., and D. K. Berg (1977) Dissociated ciliary ganglion neurons in vitro: Survival and synapse formation. Proc. Natl. Acad. Sci. USA 74: 5171-5175

Nurcombe, V., and M. R. Bennett (1981) Embryonic chick retinal ganglion cells identified in vitro. Exp. Brain Res. 44: 249-258.

O'Brien, R. J., and G. D. Fischbach (1983) Modulation of motoneuron glutamate sensitivity by interneurons in vitro. Soc. Neurosci. Abstr. 9: 1178 .

O'Brien, R. J., and G. D. Fischbach (1986a) Characterization of excitatory amino acid receptors expressed by embryonic chick motoneurons in vitro. J. Neurosci. 6: 3275-3283.

O'Brien, R. J., and G. D. Fischbach (1986b) Excitatory synaptic transmission between interneurons and motoneurons in chick spinal cord cell cultures. J. Neurosci. 6: 3284-3289.

O'Brien, R. J., and G. D. Fischbach (1986c) Modulation of embryonic chick motoneuron glutamate sensitivity by interneurons and agonists. J. Neurosci. 6: 3290-3296.

O'Brien, R. J., L. W. Role, and G. D. Fischbach (1982) Characterization of identified motoneurons in vitro. Soc. Neurosci. Abstr. 8: 129.

Okado, N., and R. W. Oppenheim (1984) Cell death of motoneurons in the chick embryo spinal cord. IX. The loss of motoneurons following removal of afferent inputs. J. Neurosci. 4: 1639-1652.

Okun, L. M. (1981) Identification and isolation in vitro of neurons marked in situ by retrograde transport. In New Approaches in Developmental Neurobiology, D. Gottlieb, ed., pp. 109-121, Society of Neuroscience, Washington, D.C.

Oppenheim, R. W. (1981) Neuronal cell death and some related regressive phenomena during neurogenesis: A selective historical review and progress report. In Studies in Development Neurobiology, Essays in Honor of Viktor Hamburger, W. M. Cowan, ed., pp. 74-133, Oxford U. P., New York.

Oppenheim, R. W., I.-W. Chu-Wang, and J. L. Maderdut (1978) Cell death of motoneurons in the chick embryo spinal cord. III. The differentiation of motoneurons prior to their induced degeneration following limb-bud removal. J. Comp. Neurol. 177: 87-112.

Rall, W. (1960) Membrane potential transients and membrane time constants of motoneurons. Exp. Neurol. 2: 503-532.

Rall, W. (1969) Time constants and electronic length of membrane cylinders and neurons. Biophys. J. 9: 1483-1508.

Ramón y Cajal, S. (1929) Studies on Vertebrate Neurogenesis, L. Guth, trans., Thomas, Springfield, Ill.

Ransom, B. R., P. N. Bullock, and P. G. Nelson (1977) Mouse spinal cord in cell culture. III. Neuronal chemosensitivity and its relationship to synaptic activity. J. Neurophysiol. 40: 1163-1177.

Redman, S. J. (1979) Junctional mechanisms at group 1a synapses. Prog. Neurobiol. 12:33-83.

Role, L. W., V. R. Matossian, R. J. O'Brien, and G. D. Fischbach (1985) On the mechanism of $\mathrm{ACh}$ receptor accumulation at newly formed synapses on chick myotubes. J. Neurosci. 5: 2197-2204.

Sarthy, P. V., B. M. Curtis, and W. A. Catterall (1983) Retrograde labelling, enrichment, and characterization of retinal ganglion cells from the neonatal rat. J. Neurosci. 3: 2532-2544.

Schaffner, A. E., P. A. St. John, and J. L. Barker (1983) Purification of embryonic mouse motoneurons by flow cytometry. Soc. Neurosci. Abstr. 9: 7.

Schnaar, R. L., and A. E. Schaffner (1981) Separation of cell types from embryonic chicken and rat spinal cord: Characterization of motoneuron enriched fractions. J. Neurosci. 1: 204-217.

Schwindt, P. C., and W. E. Crill (1984) Membrane properties of cat spinal motoneurons. Handbook of the Spinal Cord, Vols. 2 and 3 , R. A. Davidoff, ed., Marcel Dekker, New York.

Stewart, W. W. (1981) Lucifer dyes-highly fluorescent dyes for biological tracing. Nature 292: 17-21.

Van der Loos, H., and T. A. Woolsey (1973) Somatosensory cortex: Structural alterations following early injury to sense organs. Science 179: 395-398

Varon, ?, and ? Manthorpe ? (1984) ?? p. 25 